\title{
Characterising Design Process Interfaces as Organisation Networks: Insights for Engineering Systems Management
}

\author{
Pedro Parraguez, ${ }^{1}$ Steven Eppinger, ${ }^{2}$ and Anja Maier ${ }^{1}$ \\ ${ }^{I}$ Department of Management Engineering, Engineering Systems Group, Technical University of Denmark \\ (DTU), Kongens Lyngby 2800, Denmark ${ }^{2}$ MIT Sloan School of Management, Massachusetts Institute of \\ Technology, Cambridge, MA 02139, USA
}

Abstract - The engineering design literature has provided guidance on how to identify and analyse design activities and their information dependencies. However, a systematic characterisation of process interfaces between engineering design activities is missing, and the impact of structural and compositional aspects of interfaces on process performance is unclear. To fill these gaps, we propose a new approach that characterises process interfaces as organisation networks consisting of people and their interactions when performing interfacing activities. Furthermore, we provide guidance on how to test and interpret the effect of those characteristics on interface problems. As a result, we show how structural and compositional aspects of the organisation networks between information-dependent activities provide valuable insights to better manage complex engineering design processes. The proposed approach is applied to the development of a power plant, analysing 79 process interfaces. The study reveals a relationship between the structure and composition of the process interfaces and reported interface problems. Implications of this approach include the integration of information about process and organisation architectures, the systematic identification of key performance metrics associated with interface problems, and improved support for engineering managers by means of a better overview of information flows between activities.

Keywords - Process interface, interface management, design process, project management, engineering systems 


\section{INTRODUCTION}

The engineering design process can be described as a system with three interdependent domains: the process domain (a network of activities), the organisation domain (a network of people) and the product domain (a network of components). The architecture of each domain describes the dependencies and actual interactions within its elements. Interfaces are what enable those interactions as well as what makes the integration of engineering design outputs possible (Clarkson and Eckert, 2005, p. viii; Eppinger and Browning, 2012; Rechtin, 1990).

Depending on the domain, we can identify three types of interfaces: process interfaces, organisation interfaces and product interfaces. Problems at any of these interfaces may result in system failures or may add uncertainty to the design process (Felekoglu et al., 2013; Maier et al., 2009a). Consequently, understanding and active management of interfaces is essential for successful execution and for design process improvements, especially in the context of systems engineering (Jain et al., 2010; Sheard and Mostashari, 2009). This becomes particularly important in the design of large and complex engineering systems, where interdependent design activities covering different subsystems can be distributed across hundreds or thousands of engineers (Browning, 2009; de Weck et al., 2011; Madni and Sievers, 2014).

Our focus in this paper is on process interfaces. The objective is to provide an improved conceptual understanding and analytical methods regarding process domain interfaces. Process interfaces enable information flow between activities. In other words, a process interface connects interdependent pairs of activities and allows for the fulfilment of information dependencies. We characterise these process interfaces as networks of interactions between people performing interfacing activities.

Traditional network-based approaches to process planning and control, such as Critical Path Method (CPM) and Program Evaluation and Review Technique (PERT) (for a review see Elmaghraby (1995)), and more current approaches to model the process architecture (e.g. Browning (2009); Kreimeyer \& Lindemann (2011); Eppinger \& Browning (2012)), can describe if there is an information dependency between two activities, can map the intensity and importance of the information dependencies between activities, and can map the planned or the actual process sequence given activities' information dependencies (Browning, 2002; Eppinger and Browning, 2012). However, what is not sufficiently covered by current activitybased approaches modelling the process architecture is a conceptual and quantitative 
characterisation of interfaces between interdependent activities. Consequently, we don't fully understand how information dependencies between two interdependent activities are actually addressed through the network of individuals implementing the design process. This gap hinders our capacity to address common process interface problems, such as subsystem-level integration issues and delays due to process coordination problems.

To address this gap, we propose a new approach to conceptualise and systematically quantify process interfaces in terms of their network structure and composition. We claim that such network characterisation and analysis of process interfaces not only helps to better understand the nature of complex system design processes, but also helps to better manage system engineering processes. This approach expands what is in activity-based approaches typically described only as an edge connecting two activities.

With the objective of advancing the theory and practice of process interface management, we:

1) Summarise related research and identify literature gaps (sections I and II).

2) Offer a conceptual and quantitative characterisation of process interfaces (section III).

3) Test our approach with a case study of the engineering design process of a biomass power plant. For this, we use real process data from 79 process interfaces as well as questionnaires and interviews (section IV).

4) Discuss our empirical results and the impact of this approach for research and practice (section V).

\section{BACKGROUND: INTERFACES AND INTERFACE MANAGEMENT}

\section{Interfaces}

In generic terms, an interface is where two elements meet and interact. Depending on the level of abstraction, an interface can be conceived as a concrete entity existing in the 'real world' or as an element in a description. Here we model and analyse interfaces as concrete entities, with quantitatively characterisable structures and compositions, but we also review the conceptual foundations of the proposed characterisation.

In the systems engineering and engineering design literature, the nature of interfaces has been conceptualised in different ways according to the domain under study:

- In the product domain we find components (grouped in subsystems if they exist) with interactions between them that can be material, spatial, of energy flow, of information flow, 
etc. (Eppinger and Browning, 2012, chap. 3). A product interface therefore consists of the entity(ies) that allow for the interaction between two components. Such an interface can take the form of additional components, such as a set of cables and fixtures between two interacting subsystems, but can also include the physical space through which components interact.

- In the organisation domain we find people and their interactions. In the context of the engineering design process, such interactions relate to communication and are often simplified as information exchanges (Allen, 1986; Steward, 1981; Yassine et al., 1999). An organisation interface therefore consists of the entity(ies) that allow for the interaction between two people or organisational groups. Such an interface can take the form of specific people mediating the communication between two groups, but can also include the technical means used to establish such communication.

- Finally, in the process domain, we find engineering design activities with information dependencies addressed by information flows (Eppinger and Browning, 2012; Eppinger, 2001). A process interface is what enables the information flow between activities, effectively connecting a pair of activities and fulfilling their information dependencies (Durugbo et al., 2011; Morelli et al., 1995; Sosa et al., 2007). Our approach considers process interfaces as entities composed of a network of people working at the intersection of two interdependent activities - a network that exchanges and transforms information from one activity to the other. Section III further elaborates this definition and provides means to quantitatively characterise this type of interface.

In contrast to interfaces in the product or organisation domains, a precise characterisation of what constitutes a process interface is more difficult, as: 1) the elements of process interfaces are not static. For example, people associated with the interface and their information exchanges may be in constant change. Also, activities have a beginning and an end during the lifetime of the project, can reoccur, and can last from a few hours up to weeks or months, making them comparatively more dynamic than components or people. 2) An activity cannot be observed in the same form that people or components can be, as it is not a tangible element. Rather, a design activity is a set of actions performed by a person or group to fulfil some design goal in a given period of time (Sim and Duffy, 2003). 


\section{Process domain: Interface problems and interface management}

If an interface is what connects, or should allow for the connection, of two distinct elements or groups (Morris, 1997), interface problems are instances where a lower than expected performance in this connection is identified and believed to hinder the interaction between two elements or groups. In the process domain, interface problems would therefore be the result of interaction issues between interdependent activities hindering the performance of at least one of the interfacing activities.

Consistent with the view of design as a social process of information transformation (Bucciarelli, 1984; Hubka et al., 1988; Simon, 1996), we concentrate our attention on process interface problems that are the result of inadequate information exchanges and/or unsatisfactory information transformation processes between pairs of information-dependent activities. Such problems have been associated with product-system integration difficulties that can lead to considerable negative impacts on time, budget and quality (Browning and Eppinger, 2002). These process interface problems can become manifest in issues such as costly difficulties in the integration of technical subsystems due to missing information between interdependent activities, delays due to coordination problems across activities, and quality issues due to misunderstandings about interdependent technical parameters that are inputs and/or outputs across two or more activities.

Interface management can be broadly defined as the management of interactions across a common boundary (the interface) that happens between and/or within interdependent elements of the organisation, product or process domain. One key objective of interface management is preventing interface problems. Most interface management examples refer to interfaces in the product domain (e.g. Bruun et al., 2013; Lindemann et al., 2009; Rahmani and Thomson, 2011) and in the organisation domain (e.g. Eckert, 2001; Maier et al., 2009b; Sosa et al., 2007). In comparison, interface management specifically applied to the process domain has not had the same level of attention.

As identified in Browning et al. (2006); Browning \& Ramasesh (2007); and Browning (2009), an issue affecting the management of interfaces in the process domain is that process models, especially the ones based on activity networks, emphasise design activities and their overall network of dependencies. However, these process models do not pay enough attention to the flow and transformation of information that occurs between each pair of interdependent activities. Furthermore, most process models only consider information dependencies 
between activities, not the actual information flow or how work is performed at these interfaces. This limited characterisation of process interfaces is likely to be the result of two aspects. One, the level of analysis typically applied by current process models, where the attention is focused at the level of the whole activity network, and not at the level of individual interfaces. And two, in industry, project managers generally focus on overall project timing, resources and budget, overlooking more detailed interface management until something goes wrong. For these reasons, new approaches are required to provide appropriate support for project managers of complex engineering design projects and to better understand the potential sources of interface problems.

The management of process interfaces becomes considerably more challenging in larger engineering design projects (de Weck et al., 2011). In such projects, complexity increases due to the rapid growth of potential and actual interactions between and within the many people and activities found in the process (Braha and Bar-Yam, 2007). To deal with this complexity, network analysis has proved to be a useful approach to model and systematically analyse large projects (e.g. Braha and Bar-Yam, 2004; Eppinger and Browning, 2012; Parraguez and Maier, 2016). In addition, previous studies of the architectures of products, organisations and processes have identified links between the architecture of networks in those domains and performance measures (e.g. Gokpinar et al., 2010; Sosa et al., 2004). Such links can be used to elaborate on the potential relationship between the network architecture of a process interface and interface problems.

\section{Network architecture}

Process interfaces have previously not been modelled as organisation networks, therefore there is no direct evidence in the literature for a relationship between the architecture of process interfaces and interface performance or problems. However, previous studies in the context of engineering design, new product development, and innovation management have shown the existence of relationships between the networks that characterise the overall architectures of products, organisations, and processes and the different measures of project performance (for example see Cummings and Cross, (2003); Gloor et al., (2008); Kratzer et al., (2011)). As a result, we can use those relationships, and related network metrics, as starting points to examine systematically potential relationships between the organisation network of process interfaces and interface problems. 
The architecture of any network can be analysed in terms of its structural and compositional aspects (Borgatti et al., 2013; Wasserman and Faust, 1994). Both aspects have been reported to affect the performance of systems. Structural aspects describe the topological characteristics of a network's architecture. These aspects can be quantified through metrics such as network size (number of elements), density (connectivity between the elements), centralisation (the extent to which a few nodes centralise connections) and clustering coefficient (degree of grouping) (Wasserman and Faust, 1994). Previous studies of network structure in organisations and engineering projects have identified a number of relationships between network structure and performance. In contrast, compositional aspects describe the type and variety of elements (nodes) found in the studied network; this includes aspects such as group diversity (measured for example by the heterogeneity of functional areas represented in the group), the diversity of demographic characteristics in a group, or the variety of any other feature represented in a network.

Although relationships between network architecture and performance have been widely studied in a number of organisational settings (e.g. Borgatti and Foster, 2003), due to the lack of a model and method to characterise process interfaces as organisation networks, these relationships have previously not been tested at the level of each interface. Section III provides the foundations for such an analysis.

\section{ChARACTERISING DESIGN PROCESS INTERFACES AS ORGANISATION NETWORKS}

We characterise process interfaces as organisation networks between informationdependent activities. These organisation networks are comprised of the set of informationdriven interactions between those who work at interdependent activities. For people to be considered as part of an interface they need to: 1) perform work directly associated with two information-dependent activities and/or 2) perform work at one activity and exchange information with a counterpart who performs work associated with the other, interdependent, activity.

In our proposed characterisation, process interfaces combine elements from both the process and organisation domain. The process architecture maps information dependencies between activities, allowing to identify the pairs of activities for which an interface is expected. The organisation architecture maps information exchanges between people, allowing to identify information flows in the organisation; and the intersection between the architectures of the organisation and the process domain maps activities to people, allowing to 
identify the groups of people associated with each activity. Figure 1 shows the relationship between the architectures of these domains in schematic form and provides a simplified graphic representation of a process interface between activities A6 and A7.

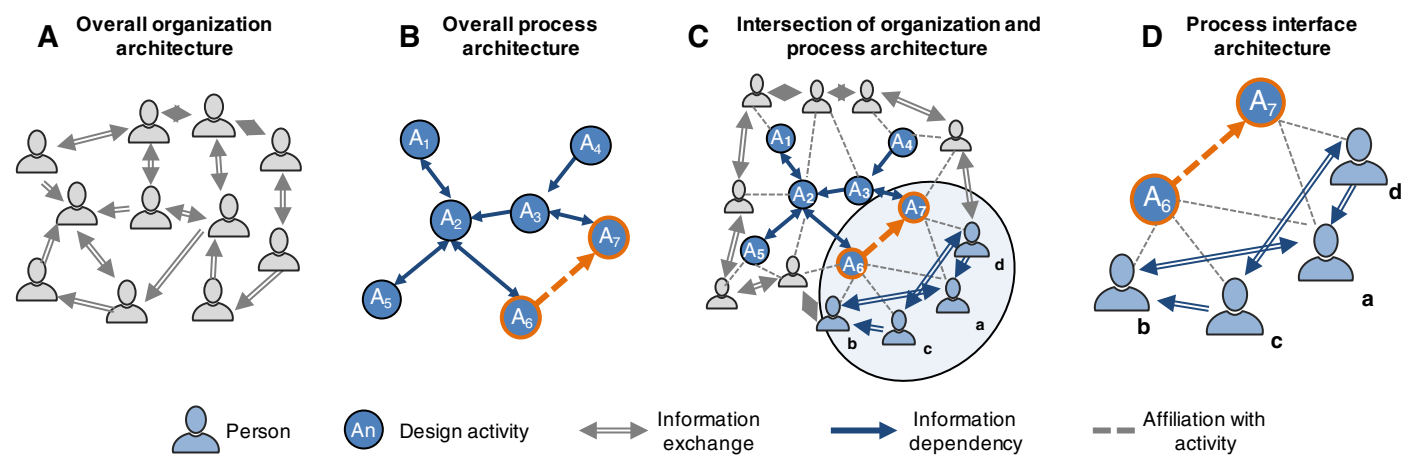

Figure 1. Conceptual model of a process interface: (A) shows the overall organization network based on information exchanges; (B) shows the activity network based on information dependencies between engineering design activities; $(\mathrm{C})$ shows the intersection between the organization and process architectures; D) shows the process interface as a combination of (A), (B), and (C).

As illustrated in figure 1, and inspired by work combining elements from the process and organisation domains (e.g. Gokpinar et al., 2010; Morelli et al., 1995; Sosa, 2008; Sosa et al., 2007), in the proposed characterisation, each process interface is described as a bi-modal network of activities and people. These (often small) networks comprise two information dependent activities, two or more people interconnected via information-driven interactions, and the mapping of each person to either one or both activities at each side of the interface.

To facilitate the analysis and interpretation, and to enable hierarchical process decomposition, activities can be grouped into cohesive work packages based on each of the subsystems being designed. Subsequently, each activity group can be associated with one of three categories: integrative work activities (activities that support, manage, and coordinate design work), integrative subsystem activities (activities that integrate two or more modular subsystems) and modular subsystem activities (design activities related to specific modules or subsystems under development) (Parraguez et al., 2015; Sosa et al., 2003). With this and the computation of structural network metrics for each process interface, it is possible to provide a structural characterisation for each process interface network. In turn, attributes such as the affiliation of each person with a functional group and the type of activity at each side of the interface provides the information required to characterise each interface's network at the compositional level (Borgatti et al., 2013; Wasserman and Faust, 1994). 
Figure 2 illustrates how this conceptual model of a process interface would apply to hypothetical activities $\mathrm{A}_{1}$ and $\mathrm{A}_{2}$. The key characteristics of this interface are:

i. Activity $\mathrm{A}_{2}$ requires information from activity $\mathrm{A}_{1}$.

ii. There are five people $\left(\mathrm{P}_{\mathrm{x}}\right)$ involved in this interface and their information exchange interactions are described in the organisation interaction matrix.

iii. $\quad \mathrm{P}_{1}$ and $\mathrm{P}_{2}$ are only affiliated with $\mathrm{A}_{1} . \mathrm{P}_{3}$ and $\mathrm{P}_{4}$ are affiliated with both activities. $\mathrm{P}_{5}$ is only affiliated with $\mathrm{A}_{2}$. This information is obtained from the person-activity affiliation matrix.

iv. In terms of composition, $\mathrm{P}_{2}, \mathrm{P}_{4}$ and $\mathrm{P}_{5}$ are from the functional group 'Engineering' (E), $\mathrm{P}_{1}$ is from the functional group 'Quality Assurance' $(\mathrm{Q})$ and $\mathrm{P}_{3}$ is from the functional group 'Project Management' (M).

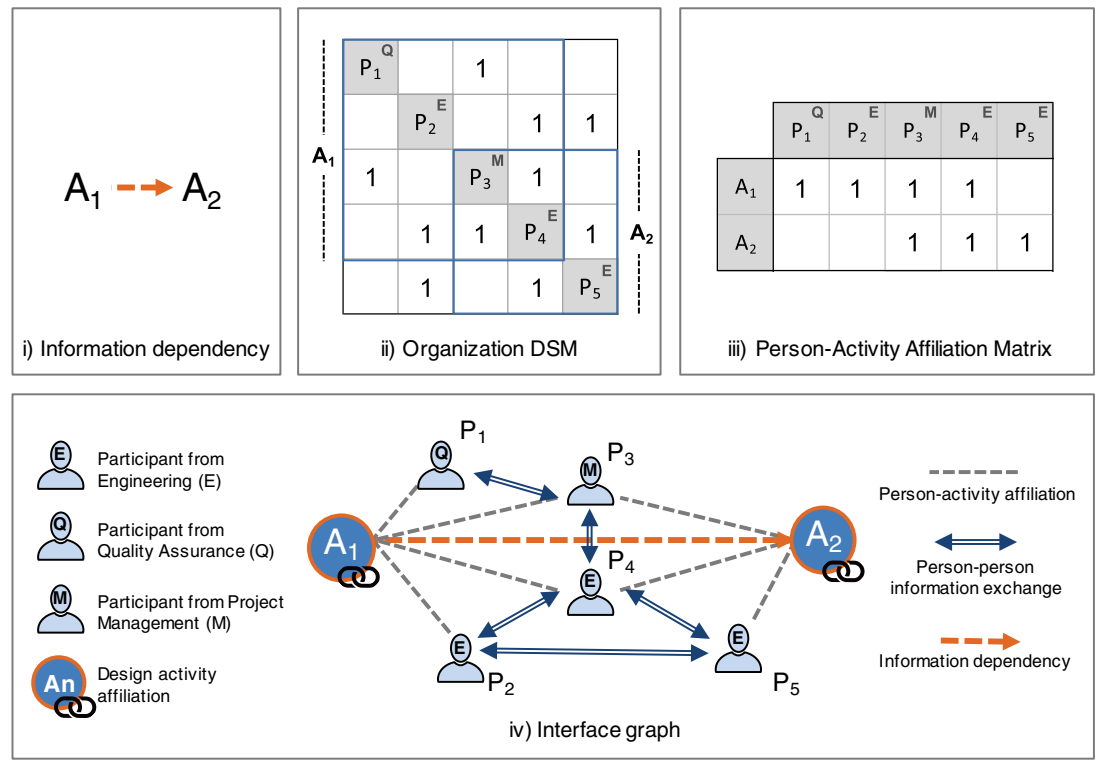

Figure 2. Information inputs for the analysis of process interfaces (generic example): (i) shows the direction of the information dependency between activities $\mathrm{A}_{1}$ and $\mathrm{A}_{2}$; (ii) shows the organization DSM matrix for people $\mathrm{P}_{1}$ to $\mathrm{P}_{5}$; (iii) shows the person-activity affiliation matrix; (iv) shows the process interface graph generated as a result of combining (i), (ii), and (iii).

Table I shows a simplified quantitative characterisation of the interface $\mathrm{A}_{1} \rightarrow \mathrm{A}_{2}$. This table includes the full set of structural and compositional aspects used in this study to characterise each process interface. 
Table I: Structural and compositional characterisation of a process interface, based on the characteristics of interface process network in figure 2 . The value for compositional diversity is calculated using the Index of Qualitative Variation (IQV)

\begin{tabular}{|c|c|c|c|c|}
\cline { 2 - 5 } \multicolumn{1}{c|}{} & \multicolumn{3}{c|}{ Structural } & Compositional \\
\cline { 2 - 5 } Explanation & Ties & $\begin{array}{c}\text { Density } \\
\text { (Size/Ties) }\end{array}$ & Compositional diversity \\
\hline people & $\begin{array}{c}\text { Number of } \\
\text { reported } \\
\text { interactions } \\
\text { between } \\
\text { people }\end{array}$ & $\begin{array}{c}\text { Ties divided } \\
\text { by number } \\
\text { of possible } \\
\text { ties: } 5 / 10\end{array}$ & $\begin{array}{c}1 \text { participant from Quality Assurance } \\
\text { 3 participants from Engineering } \\
1 \text { participant from Project Management }\end{array}$ \\
\hline Result & 5 & 5 & 0.5 & 0.84 (measured through IQV) \\
\hline
\end{tabular}

The simple set of metrics presented in table I, when analysed in the context of all process interfaces in a project, helps us to describe each interface and can be used as an input to compare the characteristics of all process interfaces and identify sources of potential problems. While the means for modelling structure and composition used here include design structure matrices and domain mapping matrices, the architecture of the process interface can be modelled using other means, including edge lists, network graphs, or any other method that allows capturing structure and attributes of a network. 


\section{The relationship between process interface architecture and performance}

Table II provides a summary of relationships found in the literature between network architecture and performance. These relationships provide the basis to examine the potential effect of the architecture of process interfaces on performance.

Table II: Examples of reported relationships between network architecture and performance

\begin{tabular}{|c|c|c|}
\hline & Structural aspects & Compositional aspects \\
\hline $\begin{array}{l}\text { Relationship } \\
\text { between } \\
\text { architecture } \\
\text { and } \\
\text { performance }\end{array}$ & $\begin{array}{l}\text { - Chen and Gable (2013) and Tsai (2001) found a } \\
\text { mostly inverted U-shaped effect between network } \\
\text { size and job performance. } \\
\text { - Burt, (1992), Easley and Kleinberg (2010) and } \\
\text { Pullen et al. (2012) found that high social network } \\
\text { density increases information flow efficiency but } \\
\text { reduces diversity of ideas. } \\
\text { - Collins et al., (2009) showed how metrics of } \\
\text { information flow based on network structure, such } \\
\text { as centrality, can be used to identify activities } \\
\text { constraining the product development execution. }\end{array}$ & $\begin{array}{l}\text { - High group heterogeneity provides access to a } \\
\text { more diverse pool of knowledge, which can } \\
\text { facilitate the development of more innovative and } \\
\text { systemic design solutions (Jansen et al., 2006; } \\
\text { Rodan and Galunic, 2004; Tsai, 2001). } \\
\text { - High heterogeneity generates communicational } \\
\text { challenges derived from the dissimilar knowledge } \\
\text { base of the participants and their different } \\
\text { perceptions of the design problem (Kleinsmann et } \\
\text { al., 2007; Tushman et al., 1980). }\end{array}$ \\
\hline
\end{tabular}

Previous studies have shown relationships between the network architecture of organisations or engineering projects and the performance of those organisations or projects (see table II for examples). Based on the evidence of those studies, it seems plausible that a relationship also exists between the structure and composition of a process interface and interface problems. For example, a U-shaped relationship can be hypothesised between network size and interface problems: Interfaces involving a larger number of participants are more likely to be affected by higher coordination costs, i.e. the costs of organising the work of the participants (Becker, 1992). In turn, interfaces with a small number of participants are more likely to be under-resourced (Chen and Gable, 2013). Likewise, a U-shaped relationship can also be expected between network density and interface problems, whereby sparsely connected networks of interactions (low density) are more likely to be inefficient in terms of information exchanges due to the higher number of intermediaries required to exchange information (Burt, 1992). In turn, dense networks, although theoretically more efficient to exchange information, might lead to or be an indicator of group-think and limit the diversity of ideas (Burt, 1992; Easley and Kleinberg, 2010; Janis, 1982). In terms of compositional diversity and interface problems, while high diversity may provide a wider range of inputs and make integration across subsystems more likely to succeed (e.g. Rodan and Galunic, 
2004; Tsai, 2001), the same diversity may lead to communication problems that hinder collaboration (e.g. Kleinsmann et al., 2007)

Interaction effects between structural and compositional network aspects, i.e. density, size and compositional diversity, are also worth considering. For example, the higher coordination costs found in larger networks can decrease if the network also has a combination of moderate to high density and low compositional diversity. In turn, an interface simultaneously involving a large number of people, with a low density and high compositional diversity can amplify coordination problems, lowering even further the information flow between the two activities and increasing the chances for misunderstandings.

While advanced network metrics can be computed and provide information about relevant network properties, caution needs to be exercised when using advanced network metrics that are substantially constrained by fundamental topological network characteristics (Faust, 2006). Moreover, focusing on size and density not only helps to avoid the problem of high multicollinearity, but also facilitates the analysis and interpretation of results, as there is clearer evidence in the literature about the effect of size and density on project performance.

The multiple possible configurations that the architectures of process interfaces can adopt, the different directions in which the same architectural characteristics can affect performance, and the highly contingent nature of design activities, together make it hard to anticipate the effect that a given process interface architecture will have on performance. For this reason, instead of aiming at developing general prescriptive guidance, we follow an alternative approach where we characterise each process interface of a design process and then analyse the relationship between sets of architectural features and the amount of interface problems in each set.

\section{Interface problems as a dependent performance variable}

In our proposed approach, the architecture of process interfaces is treated as an independent variable that we claim affects the performance of process interfaces. Considering that detailed performance measures for each process interface are often unavailable and hard to quantify with early and incomplete design process outputs, we use the existence of reported interface problems as a proxy for performance.

Although interface process problems can accumulate and propagate downstream to one or more activities and interfaces (making it difficult to identify a unique root cause), we rely on 
the estimation provided by the company to distinguish between the problems that appear to be mostly related to the inner workings of a design activity and the ones that appear to be mostly related to the interface between activities. To help with the identification of the source and location of the interface problem, the approach proposed here can be combined with approaches that use the whole process architecture to examine aspects such as change propagation e.g. (Giffin et al., 2009; Pasqual and de Weck, 2011; Wynn et al., 2014), providing in this way a more robust identification of interface problems.

\section{From interface characterisation to analysis and interpretation}

To advance from an overall process interface characterisation to a systematic analysis and interpretation, we need a method to quantify compositional diversity and analyse interfaces in the context of the whole design process in which they are embedded. Here two steps are proposed: the use of the Index of Qualitative Variation (IQV) for compositional diversity, and a combination of two-step clustering and one-way ANOVA to systematically analyse process interfaces based on their structural and compositional characteristics.

A robust and transparent method to quantify compositional diversity is found in the Index of Qualitative Variation (IQV) (Agresti and Agresti, 1977). IQV has been used in studies ranging from ecological diversity to social network analysis with the objective of calculating the relative heterogeneity of a network in terms of the variety of attributes found in the network's population (Halgin and Borgatti, 2012). This index is a normalised and continuous measure that goes from 0 to 1 . Zero means no heterogeneity (all people involved come from the same functional group) and one means maximum heterogeneity (each participating person comes from a different functional group). The IQV index is calculated as follows:

$$
I Q V=\frac{K\left(100^{2}-\sum P c t^{2}\right)}{100^{2}(K-1)} \quad \text { where, }
$$

$\mathrm{K}=$ The number of categories (for example the total number of functional groups)

$$
\sum P c t^{2}=\text { The sum of all square percentages in the distribution (as an integer number) }
$$

For example, the IQV index of a network of four members, where only four functional groups exist and each network member represents a different group (maximum heterogeneity) would be: 


$$
I Q V=\frac{4\left(100^{2}-\left(25^{2}+25^{2}+25^{2}+25^{2}\right)\right.}{100^{2}(4-1)}=1
$$

While IQV is not a metric that we found in previous engineering design studies, we believe that given its computational transparency, ease of interpretation, and flexibility to account for unlimited sample sizes and groups, it is a suitable way to quantify compositional diversity. Alternative and compatible approaches to measure compositional diversity are described in detail by Magurran (1988).

To analyse and interpret the results of our interface characterisation, we need to evaluate each interface against all other process interfaces. One way to do this is to cluster interfaces based on their structural and compositional network characteristics. If inside each cluster we find that the interfaces not only share structural and compositional characteristics, but also distinct features in aspects such as their likelihood for interface problems, we can use the clusters to analyse in additional detail the link between structure, composition, and performance issues. This approach enables a contextualised analysis of what otherwise would only be a set of individual interface characteristics without means for comparison. Additionally, clustering also helps in reducing complexity as the analysis and interpretation of the results can be performed at the level of clusters instead of at the level of each individual interface (Burns and Burns, 2008, pp. 552-558). This is particularly relevant because a large project can have hundreds or thousands of interfaces.

One method to find clusters in a set of interface cases is the two-step cluster analysis (IBM Corp, 2001). Although there are a number of other clustering methods available (Tan, 2006), we found this one to be the best suited for this kind of application. For example, unlike other clustering approaches, it can simultaneously deal with categorical and continuous variables, it is easily scalable, and it allows for manual and automatic selection of the number of clusters (IBM Corp, 2001). Using this method, each interface is assigned to one cluster based on the structural and compositional characteristics of its organisation network. The algorithm combines standard hierarchical and $\mathrm{k}$ means clustering techniques. To determine the number of clusters the Bayesian information criterion (BIC) (Schwarz, 1978) is calculated for each number of possible clusters. The model with the lowest BIC is the one used to determine the number of clusters. While in our analyses we chose the two-step clustering as our preferred clustering method, alternatives such as hierarchical clustering and $\mathrm{k}$ means clustering can also be used without significantly changing the results of the overall approach. 
Once the clusters have been identified, the question is whether those clusters have some meaningful relationship with interface problems or other aspects with implications for interface management. However, even if interface problems have not been reported yet, or their information is incomplete, we can still analyse the relative differences in key structural and compositional characteristics between the clusters and inform their interpretation based on previous studies linking organisational networks and performance. In addition, if we have at least some indication of actual interface problems, we can analyse if such problems tend to be concentrated in a few clusters or are randomly distributed. Differences in interface problems between clusters can be examined by performing a one-way ANOVA to test if any empirical difference is statistically significant (Burns and Burns, 2008, p. 284). If problems are indeed concentrated in one or only a few clusters, we can identify the particular combination of network characteristics that is associated with more interface problems, and use this information as an input to inform interface management.

An alternative to analyse the effect of process interface characteristics on performance is regression analysis. This method uses the architectural features of the interfaces as independent variables and available measures of performance as dependent variables. The advantage of this method is that it allows the modelling of a function for the relationship between the variables, and if there is a statistically significant relationship, the obtained function can be used as a predictor for the relationship between the variables. The disadvantage is that regression analysis on its own is not suitable for the identification of groups (clusters) of architectural features that affect performance in a non-linear form. Due to the expected interaction effects between the independent variables and the expected nonlinearity of their effects on performance (observed in related studies), the combination of clustering and one-way analysis of variance to test for statistical differences among the clusters, provides a more suitable approach that can be complemented by regression-type analyses to gain additional insights. 
Figure 3 shows a graphical summary of our methodological approach for process interface characterisation and analysis.

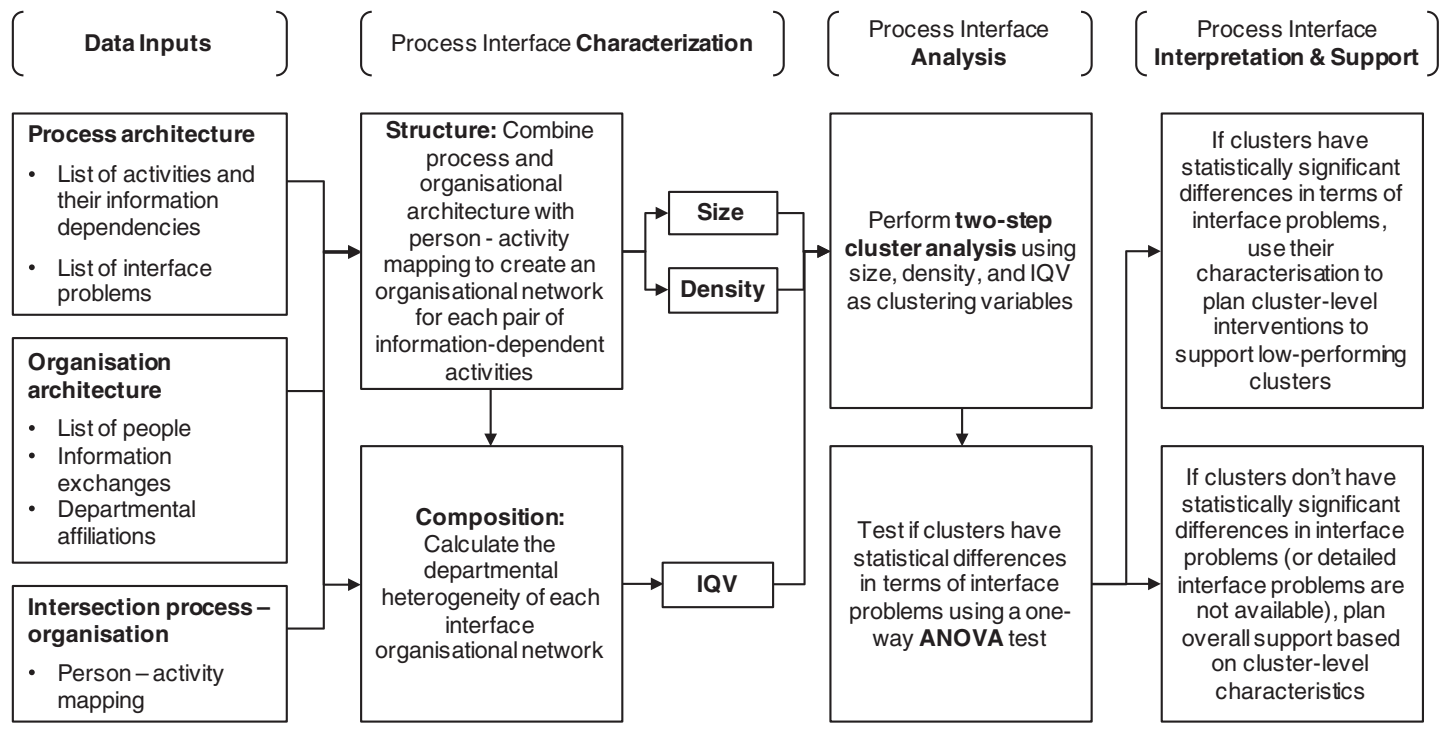

Figure 3. Summary of our approach to analyze process interfaces.

\section{CASE STUdy}

We applied our process interface model to a large engineering design project. The project consisted of the complete engineering work of a biomass power plant developed mostly in the period between 2010 and 2013. Our objective was to better understand a wide set of issues that the company commonly identified as 'interface problems' but for which causes remained unclear. Although the company had not identified the root causes or clear patterns behind their interface problems, the belief was that the majority of problems were a combination of process and organisation architecture issues. In other words, a combination of factors related to information dependencies between activities and how people interacted to address those information dependencies. Our approach, which explicitly integrates the process and organisation domains, was therefore considered appropriate to reveal patterns and provide insights into the possible sources of the problems and potential solutions.

Access to the project data was gained through the company in charge of the engineering design of the plant. The same company coordinated the work with the construction partner and component suppliers. Key contact points during this study were the VP of Operations, the VP of Engineering, the Project Manager, and the Quality Assurance team, who were all interviewed to document the process architecture and to identify interface problems. 
Data concerning interactions between the project members were obtained through an online questionnaire applied towards the end of the project. The questionnaire was completed by all 49 core project members (see also table III). They reported interactions for a total of 77 (core and non-core) project members. The question asked to elicit the overall organisation architecture reads: Please select who you have interacted with inside the company in the context of the power plant design - An interaction here is defined as work-related direct information exchanges necessary to do one or more project activities (This includes emails, work conversations and other forms of work communications). For each reported interaction there was a follow-up question to rank on a three-point scale both the impact (low, medium, high) and frequency (daily, weekly, monthly) of the interactions. Information obtained through the questionnaire was cross-validated against an email database with over 15.000 filtered project emails covering the entirety of the project life. The result of this crossvalidation showed that $58 \%$ of the reported interactions had a near complete correspondence with email communication, while $68 \%$ had a frequency-weighted correspondence of $70 \%$ or more. As a result of this cross-validation, we consider the responses obtained through the questionnaire a good proxy for actual organisational interactions.

Information dependencies between the activities were obtained through company documentation, including detailed workflow diagrams, and subsequently refined through interviews to complete a process-type DSM. The mapping of people to activities was obtained through information reported directly by each of the 49 core members in the same questionnaire applied to obtain the interactions between project members. This peopleactivity mapping was subsequently validated and refined through company records in the form of activity logs (used by the company as a way of keeping track on engineering hours spent on the project). Finally, interface problems were obtained through interviews with all of our key contact points at the company and cross-checked against company internal records of non-conformity reports. More details about the data gathered in this case study are provided in table III. 
Table III: Overall summary of gathered data

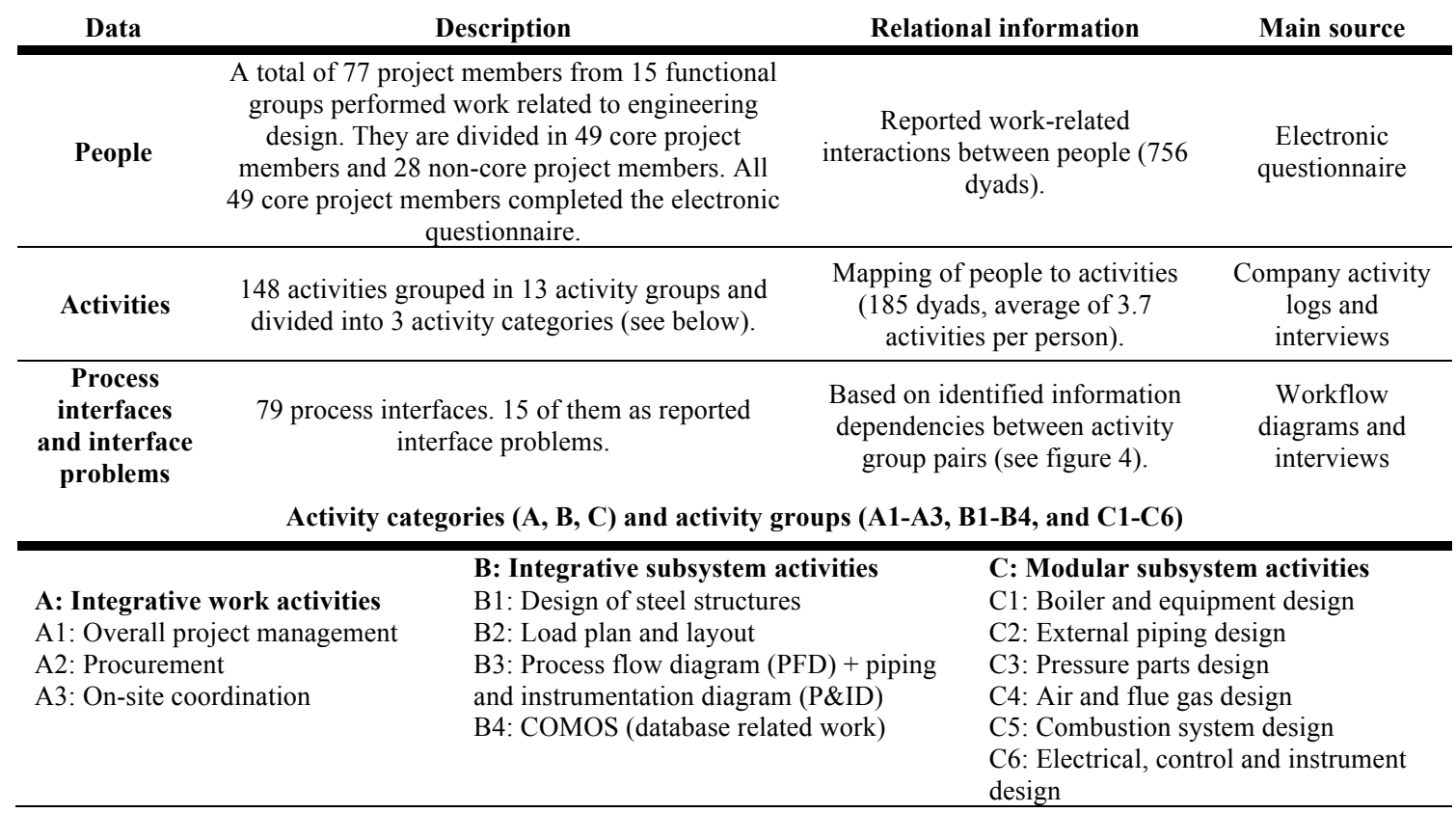

\section{Interface problems}

Issues identified during the interviews as 'interface problems' were mapped to the acquired process architecture and associated with specific process interfaces (see figure 4). Only interface problems associated with the engineering design process were elicited. Therefore, the assumption is that each interface problem emerges and can be traced back to design process issues between activities belonging to different subsystems. The most common interface problems were related to one or more of the following aspects:

- Information regarding technical specifications or procurement requirements, which should have been transferred between specific design activities, was missing. For example, in the interface problem 'Pressure parts design $\rightarrow$ Procurement', the purchase order for an important part was late, affecting the process schedule.

- Required interfaces between components of different subsystems were not aligned or fully compatible due to technical specification issues. For example, in the interface "Air and flue gas $\rightarrow$ Design of steel structures', a problem was detected in the specifications for the steel supporting the air and flue gas subsystem.

- Spatial clashes existed between parts or components belonging to different subsystems under development. For example, in the interface problem 'Boiler and equipment design 
$\rightarrow$ Pressure parts design', spatial clashes were identified between grill tubes, pipes, and boiler equipment.

- Other general misunderstandings or coordination issues were identified between specific design activities that hindered the perceived performance of one activity at the interface.

Figure 4 shows all 79 process interfaces considered in this case, as well as the distribution of interfaces with or without problems (a total of 15 problems out of 79 interfaces). The process architecture was built as a binary process-type DSM using the convention of inputs in columns (Eppinger and Browning, 2012, p. 5) and allowing interfaces and interface problems to exist in one or both directions; that is, the matrix represents a directed graph.

\begin{tabular}{|c|c|c|c|c|c|c|c|c|c|c|c|c|}
\hline & \begin{tabular}{|c|} 
Air and Flue \\
Gas
\end{tabular} & $\begin{array}{l}\text { Boiler and } \\
\text { Equipment } \\
\text { Design }\end{array}$ & $\begin{array}{c}\text { Combustion } \\
\text { System }\end{array}$ & сомоs Data & $\begin{array}{c}\text { Electrical } \\
\text { Control and } \\
\text { Instrument. }\end{array}$ & $\begin{array}{c}\text { External } \\
\text { Piping }\end{array}$ & $\begin{array}{l}\text { Load Plan } \\
\text { and Layout }\end{array}$ & $\begin{array}{l}\text { Overall Proj. } \\
\text { Manag. }\end{array}$ & PFD + P\&ID & \begin{tabular}{|c|} 
Pressure \\
Parts Design
\end{tabular} & Procurement & $\begin{array}{l}\text { Design of } \\
\text { Steel } \\
\text { Structures }\end{array}$ \\
\hline Air and Flue Gas & & & & $\checkmark$ & $\checkmark$ & & $\checkmark$ & $\checkmark$ & $\checkmark$ & & $\checkmark$ & $x$ \\
\hline $\begin{array}{c}\text { Boiler and } \\
\text { Equipment Design }\end{array}$ & $\checkmark$ & & $\checkmark$ & $\checkmark$ & $\checkmark$ & $\checkmark$ & & $\checkmark$ & & $x$ & & \\
\hline Combustion System & & & & $\checkmark$ & $\checkmark$ & & $x$ & $\checkmark$ & & & $\checkmark$ & \\
\hline comos Data & $\checkmark$ & & $\checkmark$ & & $\checkmark$ & $\checkmark$ & & $\checkmark$ & $\checkmark$ & $\checkmark$ & & \\
\hline $\begin{array}{c}\text { Electrical Control } \\
\text { and Instrumentation }\end{array}$ & $\checkmark$ & & $\checkmark$ & $\checkmark$ & & $\checkmark$ & & $\checkmark$ & $\checkmark$ & $x$ & $\checkmark$ & \\
\hline External Piping & & & & $\nu$ & $\checkmark$ & & $\checkmark$ & $\checkmark$ & $\checkmark$ & $x$ & $x$ & $x$ \\
\hline $\begin{array}{l}\text { Load Plan and } \\
\text { Layout }\end{array}$ & & & & & & & & $\checkmark$ & & & & $\checkmark$ \\
\hline $\begin{array}{c}\text { Overall Project } \\
\text { Management }\end{array}$ & $\checkmark$ & $\checkmark$ & $\checkmark$ & $\checkmark$ & $\checkmark$ & $\checkmark$ & $\checkmark$ & & $\checkmark$ & $x$ & $x$ & $\checkmark$ \\
\hline PFD + P\&ID & $\checkmark$ & $\checkmark$ & $\checkmark$ & $\checkmark$ & $\checkmark$ & $\checkmark$ & & $\checkmark$ & & $\checkmark$ & & \\
\hline $\begin{array}{c}\begin{array}{c}\text { Pressure Parts } \\
\text { Design }\end{array} \\
\end{array}$ & & & & $\checkmark$ & $x$ & & $\checkmark$ & $x$ & $\checkmark$ & & $x$ & \\
\hline Procurement & $\checkmark$ & & $\checkmark$ & & $\checkmark$ & $x$ & & $x$ & & $x$ & & $\checkmark$ \\
\hline $\begin{array}{c}\text { Design of Steel } \\
\text { Structures }\end{array}$ & & & & & & & $\checkmark$ & $\checkmark$ & & & $\checkmark$ & \\
\hline
\end{tabular}

Figure 4. Process design structure matrix: interfaces and interface problems. The matrix shows all 79 process interfaces identified using the convention of inputs in columns (for example, "Design of Steel Structures" require information from "Air and Flue Gas"). Problem interfaces are marked with an $\mathrm{X}$, those with no problem have a checkmark.

\section{Characterisation of Process Interfaces}

Figure 5 provides a graph-based characterisation for three of the 79 process interfaces, which were selected to illustrate various combinations of size, density, and IQV. Following our proposed approach, interfaces are represented as organisation networks between two activities and coloured to indicate their affiliation to functional groups. 


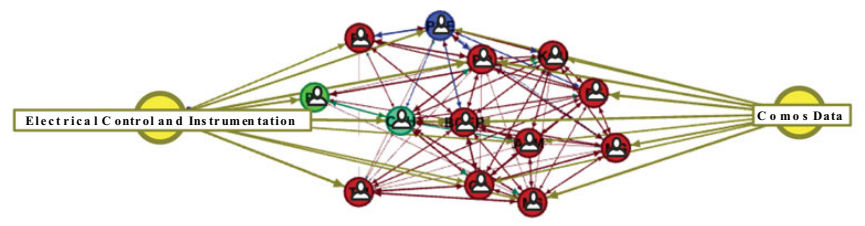

A Electrical Control and Instrumentation $\leftrightarrow$ Comos Data

No interface problem

Size: 15 - Density: $76 \%$ - IQV: 0.583

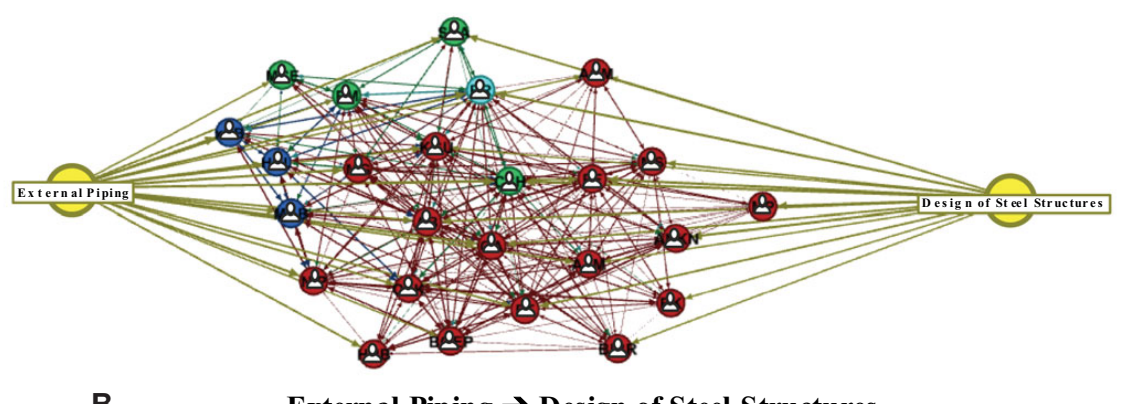

B External Piping $\rightarrow$ Design of Steel Structures

Interface problem has been reported

Size: 27 - Density: 68\% - IQV: 0.625

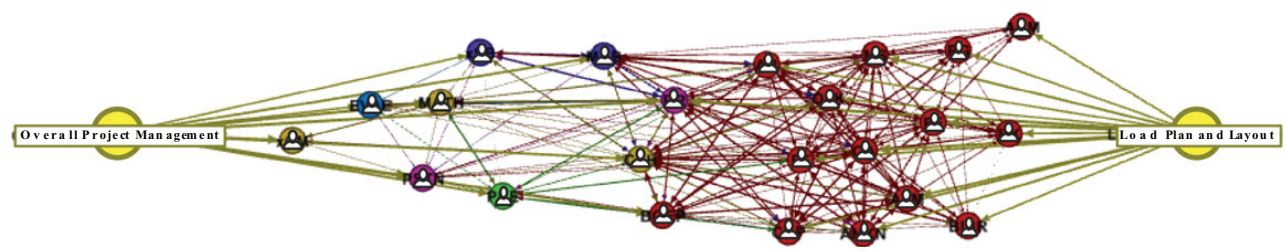

C Overall Project Management $\leftrightarrow$ Load Plan and Layout

No interface problem

Size: 25 - Density: 62\% - IQV: 0.722

Figure 5. Three graphical examples of actual process interface characterizations. The graph layout is weighted and force-directed to represent different intensities of information exchanges. Edges map people to activities and people-people interactions. Project members are colored according to their functional affiliation to a group. The far right and far left nodes represent the activities.

Through an inspection of the three examples we can see some of the following architectural features:

- Process interface A): Electrical Control and Instrumentation $\Leftrightarrow$ Comos Data (bi-directional dependency, no interface problem) shows a relatively small, dense network with low diversity. Only one cohesive group is distinguishable.

- Process interface B): External Piping $\Rightarrow$ Design of Steel Structures (uni-directional dependency, interface problem) is a larger, slightly sparser network. One cohesive group is still distinguishable; however, members from the same functional group tend to group together. 
- In contrast to the other two examples, process interface C): Overall Project Management $\Leftrightarrow$ Load Plan and Layout (bi-directional dependency, no interface problem) is noticeable fragmented, with one cohesive and relatively homogeneous group (to the right of the graph) and a second sparse, cross-functional group to the left.

To move from a descriptive characterisation of interface to a systematic analysis we applied (a) a two-step clustering analysis in which similar interfaces were grouped, and (b) a one-way ANOVA test to identify significance of the amount of interface problems across the identified clusters.

\section{Process Interface Analysis}

a) Two-step clustering analysis

For the cluster analysis (results in figure 6), the 'distance measure' used was log-likelihood, and the number of clusters was set to be determined automatically based on the Schwarz's Bayesian information criterion (BIC). Three distinct groups with a 'silhouette measure of cohesion and separation' of 0.6 were obtained, which indicates good cluster quality (Tan, 2006).

\begin{tabular}{|c|c|c|c|c|}
\hline & Iluster ID & 1 & 2 & 3 \\
\hline inter & $\begin{array}{l}\text { lumber of } \\
\text { es in the cluster }\end{array}$ & $13(16 \%)$ & $38(48 \%)$ & $28(36 \%)$ \\
\hline \& & Network size & & & \\
\hline 일 & Network density & & & \\
\hline$\frac{2}{0}$ & $\begin{array}{c}\text { IQV } \\
\begin{array}{c}\text { (Compositional } \\
\text { Diversity) }\end{array}\end{array}$ & & & \\
\hline & & of the variab & & \\
\hline $\begin{array}{r}\text { Numb } \\
\text { pre }\end{array}$ & $\begin{array}{l}\text { Interfaces with } \\
\text { ms in cluster }\end{array}$ & $8(62 \%)$ & $4(11 \%)$ & $3(11 \%)$ \\
\hline
\end{tabular}

Figure 6. Graphical characterization for the three identified clusters. The size, density, and diversity of the interfaces' organization networks were utilized as clustering variables. For each cluster, the relative distributions of clustering variables are shown as plots.

The analysis revealed the following characteristics for the three clusters identified:

- Cluster 1 contains $16 \%$ of all interfaces. Interfaces in this cluster are characterised by a large number of people, low density, and medium heterogeneity. This cluster was composed mainly of interfaces between the design activity of 'pressure parts design' and other modular as well as integrative subsystem design activities. Despite the few 
interfaces assigned to cluster 1 (16\% of the total), a majority of the interfaces in this cluster (62\%) experienced problems (8 out of 13$)$.

- Cluster 2 contains $48 \%$ of all interfaces. Interfaces in this cluster are characterised by a medium number of people, medium to low density, and high heterogeneity. This cluster is composed mainly of interfaces between integrative work (project management and procurement) and modular subsystem design activities. This cluster contains only 4 interfaces with problems (out of 38).

- Cluster 3 contains $35 \%$ of all interfaces. Interfaces in this cluster are characterised by a low number of people, high density, and low heterogeneity. This cluster is composed mainly of interfaces between modular and subsystem design activities and has only 3 interfaces with problems (out of 28).

b) Examining interface problem differences across clusters through the one-way ANOVA test.

We used a one-way ANOVA test to understand if there were statistically significant differences in the proportion of interface problems between the clusters. The results indicated a highly significant $(\mathrm{p}<0.01)$ difference in the proportion of problems between the clusters, confirming the finding that the network characteristics of cluster 1 were associated with a greater likelihood of interface problems. Therefore, for this case study, interface problems were more likely to arise among interfaces with a larger number of participants and whose interactions had a relatively low density.

In addition to the clustering and one-way ANOVA analysis, a logistic regression was performed to estimate the effects of network size, density, and IQV on the likelihood of an interface experiencing problems. The logistic regression model was statistically significant only for size, with $p<.005$ (0.22 coefficient), and explained 28.0\% (Nagelkerke $R^{2}$ ) of the variance in interface problems. This revealed that network size was associated with an increased likelihood of exhibiting interface problems, however, unlike two-step clustering, logistic regression was unable to account for the effects of density and IQV. 


\section{Interpretation of the case study results and implications}

To move from understanding to data-driven support and targeted interventions, the characterisation and analysis previously performed is insufficient on its own to support project management. Fortunately, organisational and social network studies have provided prescriptions that can be used as a guide for dealing with the different types of network architectures found in each cluster:

- Cluster 1: The analysis indicates that interfaces found in this cluster, with interface networks higher in size and lower in density, are significantly more likely to have problems. From previous research (Burt, 1992; Chen and Gable, 2013; Tsai, 2001), we can infer that interfaces in this cluster were exposed to higher coordination costs, which could constrain information flows between activities. Strategies to mitigate these problems include: 1) increasing the organisational connectivity by enabling more direct contact between the members of this interface, 2) allocating more resources to people who mediate interactions, as information brokerage roles such as the one described by Gould and Fernandez (1989) can increase efficiency of information exchanges, and 3) reducing the number of interfaces which couple multiple activities to create more focused interfaces with fewer people each, which has been found to be an effective way to manage complexity and improve modularity (Eppinger and Browning, 2012, p. 146; Steward, 1981).

- Cluster 2: Although reported interface problems are not high in this cluster, the main challenge is how to handle the interface networks' relatively high heterogeneity. Previous studies have shown that high functional group diversity increases the likelihood of miscommunication and misalignment of objectives (Kleinsmann et al., 2007; Tushman et al., 1980). To mitigate these potential problems and benefit from the knowledge diversity inherent in heterogeneity, efforts should be made to ensure there are enough well connected individuals at the centre of the interface. These individuals should be able to bridge and translate different knowledge bases and align objectives, building capabilities to work across boundaries. In addition, as Maier, Kreimeyer, et al. (2009) suggested, more reflective communication and overview that explicates each party's informational needs could be particularly helpful when dealing with cross-disciplinary interfaces.

- Cluster 3: Based on the relatively low number of reported problems, small size, high density, and low heterogeneity of the interfaces in this cluster, interface management here 
should be comparatively simpler. Nevertheless, these characteristics also may lead to groupthink and a lack of systemic perspective because of the narrower knowledge pool available in this cluster (Burt, 1992; Easley and Kleinberg, 2010; Janis, 1982). As a result, additional, more diverse resources to increase heterogeneity could be beneficial, especially for interfaces dealing with central activities in the process that require a systemic perspective, or for interfaces that have the objective of producing innovative results.

\section{DisCUSSION AND CONCLUSIONS}

By characterising process interfaces as organisation networks we have provided a more detailed understanding of how information dependencies between design activities are actually executed and managed. The proposed approach models each process interface as a socio-technical network of activities and people, connecting activity-based models of the design process with engineering design theory that describes design as a social process. This characterisation generates a platform for further research and analysis of the actual design process, enabling the comparison of the actual process with planned or idealised process models. In addition, through the application of the proposed approach in an industrial setting we provided a pilot study that serves as a test of the feasibility and usefulness of such an approach in the context of systems engineering.

Managerial implications include the provision of new tools to facilitate the work and decision-making processes of project and interface managers. The application of our approach in the company resulted in 1) an improved overview of process interfaces based on quantitative characteristics and identifiable clusters, 2) allowed to narrow down support efforts on the cluster of interfaces that concentrated most of the problems, 3) contributed to the creation of a new job position ('interface lead'), and 4) allowed to map and actively manage process interfaces using customised evidence-driven support strategies for each interface cluster.

Research implications include advancing the understanding of what constitutes a process interface, bridging the architectures of process and organisation domains, and characterising process interfaces for the first time as organisation networks. This directly contributes to addressing the need raised by (Browning and Ramasesh, 2007; Browning, 2009; Browning et al., 2006) for going beyond only stating information dependencies and advancing towards a more detailed understanding of the design process that also includes how the information is 
delivered and transformed between each pair of activities. We also found statistically significant evidence suggesting a positive correlation between interface problems and process interfaces that are characterised by high network size, low network density and medium compositional diversity. This finding and the set of basic network metrics proposed to characterise the structure and composition of process interfaces can be used and expanded in future studies.

A relevant consideration that can affect the implementation and results obtained from our approach relates to the hierarchical decomposition used when listing the activities and its nonunique nature (multiple decompositions are possible) (e.g. Li 2011). A more detailed hierarchical decomposition will lead to a longer list of activities. This translates into more and smaller process interfaces and, as an extreme result, process interfaces with only one or two participants. A more aggregated decomposition will lead to fewer activities, more encompassing process interfaces and, as an extreme result, process interfaces containing large parts of the organisational network. Either of these extremes would lead to the loss of important information about the design context and can hinder our possibility to identify statistical relationships between network characteristics and interface problems. Therefore, the activity list should be as detailed as feasible given time and cost considerations. Afterwards, with a detailed list, activities can be aggregated to a level that appropriately fits the analytical needs and also better matches the hierarchical decomposition applied in the product and the organisation domain.

A limitation of the presented approach (in its current form) is that, as is often the case with network and complexity studies, it cannot identify causality but only association between the variables under study (Kreimeyer and Lindemann, 2011; Wasserman and Faust, 1994). The real causes of interface problems and their directionality can be studied complementing this approach with carefully designed controlled interventions in companies. Another limitation is that although each process interface is modelled as an individual network, in reality, each of these networks is embedded in the overall process architecture. This means that each organisation network describing a process interface is not independent and that the members of one process interface might also be part of other interfaces. The approach we follow to deal with this issue is analogous to the one applied in ego-network analyses of social and technical networks, in which the interdependency is acknowledged, but is only addressed at the whole network level (Wasserman and Faust, 1994, p. 41). In our analysis, the 'ego' network is the edge between interdependent activities (the interface) instead of the node (the activity). The 
analysis and interpretation at the interface level can therefore be performed independently, provided that the conclusions remain at the same level. For complementary analyses at the activity and whole process levels see (Parraguez and Maier, 2015; Parraguez, 2015; Parraguez et al., 2015).

In addition to network size, density and IQV, other network metrics can be computed and provide information about relevant network properties and their effect on performance. However, as Faust (2006) points out, caution needs to be exercised when using advanced network metrics that are substantially constrained by fundamental topological network characteristics. Moreover, focusing first on size and density not only helps to avoid the problem of high multicollinearity in network studies, but also facilitates the analysis and interpretation of results as there is clearer evidence in the literature about their effect on project performance.

Further studies can continue developing the proposed approach through the inclusion of more and specifically tailored network and non-network metrics to quantify the structural and compositional characteristics of each interface. The architectural metrics of size, density and compositional diversity are hence only starting points in terms of possible analyses. Also, additional case studies covering different industries and contexts would allow identifying if there is a set of interface characteristics that consistently correlate with interface problems and that could therefore be generalised. 


\section{REFERENCES}

Agresti, A., Agresti, B.F., 1977. Statistical Analysis of Qualitative Variation. In: Schuessler, K.F. (Ed.), Sociological Methodology. Jossey-Bass, San Francisco, pp. 204-237.

Allen, T., 1986. Organizational structure, information technology and R\&D productivity. IEEE Transactions on Engineering Management EM-33, 212-217.

Becker, G., 1992. The Division of Labor, Coordination Costs, and Knowledge. The Quarterly Journal of Economics 107, $1137-1160$.

Borgatti, S., Everett, M.G., Johnson, J.C., 2013. Analyzing Social Networks. SAGE Publications, London.

Borgatti, S., Foster, P., 2003. The Network Paradigm in Organizational Research: A Review and Typology. Journal of Management 29, 991-1013.

Braha, D., Bar-Yam, Y., 2004. Topology of large-scale engineering problem-solving networks. Physical Review E 69, 1-7.

Braha, D., Bar-Yam, Y., 2007. The Statistical Mechanics of Complex Product Development: Empirical and Analytical Results. Management Science 53, 1127-1145.

Browning, T.R., 2002. Process integration using the design structure matrix. Systems Engineering 5, 180-193.

Browning, T.R., 2009. The Many Views of a Process: Toward a Process Architecture Framework for Product Development Processes. Systems Engineering 12, 69-90.

Browning, T.R., Eppinger, S.D., 2002. Modeling impacts of process architecture on cost and schedule risk in product development. IEEE Transactions on Engineering Management 49, 428-442.

Browning, T.R., Fricke, E., Negele, H., 2006. Key concepts in modeling product development processes. Systems Engineering 9, 104-128.

Browning, T.R., Ramasesh, R. V, 2007. A Survey of Activity Network-Based Process Models for Managing Product Development Projects. Production and Operations Management 16, 217-240.

Bruun, H.P.L., Mortensen, N.H., Harlou, U., 2013. Interface diagram: Design tool for supporting the development of modularity in complex product systems. Concurrent Engineering: Research and Applications 22, 62-76.

Bucciarelli, L.L., 1984. Reflective Practice in Engineering Design. Design Studies 5, 185-190.

Burns, R.P., Burns, R., 2008. Business Research Methods and Statistics Using SPSS. SAGE.

Burt, R.S., 1992. The social structure of competition. In: Nohria, N., Eccles, R.G. (Eds.), Networks and Organizations: Structure, Form, and Action. Harvard Business School Press, Boston, pp. 57-91.

Chen, L., Gable, G.G., 2013. Larger or Broader: Performance Implications of Size and Diversity of the Knowledge Worker's Egocentric Network. Management and Organization Review 9, 139-165.

Clarkson, P.J., Eckert, C.M., 2005. Design process improvement: A review of current practice. Springer London, London.

Collins, S.T., Yassine, A.A., Borgatti, S., 2009. Evaluating Product Development Systems Using Network Analysis. Systems Engineering 12, 55-68.

Cummings, J.N., Cross, R., 2003. Structural properties of work groups and their consequences for performance. Social Networks 25, 197-210.

de Weck, O., Roos, D., Magee, C.L., 2011. Engineering Systems: Meeting Human Needs in a Complex Technological World. The MIT Press, Cambridge.

Durugbo, C., Hutabarat, W., Tiwari, A., Alcock, J.R., 2011. Modelling collaboration using complex networks. Information Sciences 181, 3143-3161.

Easley, D., Kleinberg, J., 2010. Networks, Crowds, and Markets: Reasoning About a Highly Connected World. Cambridge University Press, Cambridge. 
Eckert, C.M., 2001. The Communication Bottleneck in Knitwear Design: Analysis and Computing Solutions. Computer Supported Cooperative Work (CSCW) 10, 29-74.

Elmaghraby, S.E., 1995. Activity nets: A guided tour through some recent developments. European Journal of Operational Research 82, 383-408.

Eppinger, S.D., 2001. Innovation at the Speed of Information. Harvard Business Review 149-158.

Eppinger, S.D., Browning, T.R., 2012. Design Structure Matrix Methods and Applications. The MIT Press, Cambridge.

Faust, K., 2006. Comparing Social Networks: Size, Density, and Local Structure. Metodološki zvezki 3, 185216.

Felekoglu, B., Maier, A.M., Moultrie, J., 2013. Interactions in new product development: How the nature of the NPD process influences interaction between teams and management. Journal of Engineering and Technology Management 30, 384-401.

Giffin, M., de Weck, O.L., Bounova, G., Keller, R., Eckert, C., Clarkson, P.J., 2009. Change Propagation Analysis in Complex Technical Systems. Journal of Mechanical Design 131, 081001.

Gloor, P.A., Paasivaara, M., Schoder, D., Willems, P., 2008. Finding collaborative innovation networks through correlating performance with social network structure. International Journal of Production Research 46, $1357-1371$.

Gokpinar, B., Hopp, W., Iravani, S., 2010. The Impact of Misalignment of Organizational Structure and Product Architecture on Quality in Complex Product Development. Management Science 56, 468-484.

Gould, V., Fernandez, R.M., 1989. Structures of Mediation: A Formal Approach to Brokerage in Transaction Networks. Sociological methodology 19, 89-126.

Halgin, D.S., Borgatti, S., 2012. An Introduction to Personal Network Analysis and Tie Churn Statistics using ENET. LINKS Center for Social Network Analysis, University of Kentucky, Kentucky, KY.

Hubka, V., Andreasen, M.M., Eder, W.E., 1988. Practical Studies in Systematic Design. ButterworthHeinemann, London.

IBM Corp, 2001. SPSS two-step cluster analysis.

Jain, R., Chandrasekaran, A., Erol, O., 2010. A systems integration framework for process analysis and improvement. Systems Engineering 13, 274-289.

Janis, I.L., 1982. Groupthink: psychological studies of policy decisions and fiascoes. Houghton Miffli, Boston.

Jansen, J.J.P., Van Den Bosch, F.A.J., Volberda, H.W., 2006. Exploratory Innovation, Exploitative Innovation, and Performance: Effects of Organizational Antecedents and Environmental Moderators. Management Science 52, 1661-1674.

Kleinsmann, M., Valkenburg, R., Buijs, J., 2007. Why do(n’t) actors in collaborative design understand each other? An empirical study towards a better understanding of collaborative design. CoDesign 3, 59-73.

Kratzer, J., Gemuenden, H., Lettl, C., 2011. The Organizational Design of Large R\&D Collaborations and Its Effect on Time and Budget Efficiency: The Contrast Between Blueprints and Reality. IEEE Transactions on Engineering Management 58, 295-306.

Kreimeyer, M., Lindemann, U., 2011. Complexity Metrics in Engineering Design: Managing the Structure of Design Processes. Springer, London.

Li, S., 2011. A matrix-based clustering approach for the decomposition of design problems. Research in Engineering Design 22, 263-278.

Lindemann, U., Maurer, M.S., Braun, T., 2009. Structural Complexity Management. Springer, Berlin.

Madni, A.M., Sievers, M., 2014. Systems Integration: Key Perspectives, Experiences, and Challenges. Systems Engineering 17, 37-51.

Magurran, A.E., 1988. Ecological Diversity and Its Measurement. Springer, Dordrecht. 
Maier, A.M., Eckert, C.M., Clarkson, P.J., 2009a. Towards managing team interfaces: An elicitation of factors influencing communication. In: Proceedings of the 17th International Conference on Engineering Design (ICED 2009). Stanford, pp. 275-286.

Maier, A.M., Kreimeyer, M., Lindemann, U., Clarkson, P.J., 2009b. Reflecting communication: a key factor for successful collaboration between embodiment design and simulation. Journal of Engineering Design 20, $265-287$.

Morelli, M.D., Eppinger, S.D., Gulati, R.K., 1995. Predicting technical communication in product development organizations. IEEE Transactions on Engineering Management 42, 215-222.

Morris, P.W.G., 1997. Managing project interfaces - Key points for project success. In: Cleland, D.I., King, W.R. (Eds.), Project Management Handbook. John Wiley \& Sons, Inc., Hoboken, NJ, USA, pp. 16-55.

Parraguez, P., 2015. A Networked Perspective on the Engineering Design Process: At the Intersection of Process and Organisation Architectures. PhD Thesis, Technical University of Denmark.

Parraguez, P., Eppinger, S.D., Maier, A.M., 2015. Information Flow Through Stages of Complex Engineering Design Projects: A Dynamic Network Analysis Approach. IEEE Transactions on Engineering Management 62, 604-617.

Parraguez, P., Maier, A.M., 2015. Unfolding the Design Process Architecture: A Networked Perspective on Activities. In: International Conference on Engineering Design 2015 (ICED 2015). Milan.

Parraguez, P., Maier, A.M., 2016. Using network science to support design research: From counting to connecting. In: Cash, P., Stankovic, T., Storga, M. (Eds.), Experimental Design Research: Approaches, Perspectives, Applications. Springer.

Pasqual, M.C., de Weck, O., 2011. Multilayer network model for analysis and management of change propagation. Research in Engineering Design 23, 305-328.

Pullen, A.J.J., de Weerd-Nederhof, P.C., Groen, A.J., Fisscher, O. a. M., 2012. Open Innovation in Practice: Goal Complementarity and Closed NPD Networks to Explain Differences in Innovation Performance for SMEs in the Medical Devices Sector. Journal of Product Innovation Management 29, 917-934.

Rahmani, K., Thomson, V., 2011. Managing subsystem interfaces of complex products. International Journal of Product Lifecycle Management 5, 73.

Rechtin, E., 1990. Systems Architecting: Creating \& Building Complex Systems. Prentice Hall, Michigan.

Rodan, S., Galunic, C., 2004. More than network structure: how knowledge heterogeneity influences managerial performance and innovativeness. Strategic Management Journal 25, 541-562.

Schwarz, G., 1978. Estimating the Dimension of a Model. The Annals of Statistics 6, 461-464.

Sheard, S.A., Mostashari, A., 2009. Principles of Complex Systems for Systems Engineering. Systems Engineering 12, 295-311.

Sim, S.K., Duffy, A.H.B., 2003. Towards an ontology of generic engineering design activities. Research in Engineering Design 14, 200-223.

Simon, H.A., 1996. The Sciences of the Artificial. The MIT Press, Cambridge.

Sosa, M.E., 2008. A structured approach to predicting and managing technical interactions in software development. Research in Engineering Design 19, 47-70.

Sosa, M.E., Eppinger, S.D., Rowles, C.M., 2003. Identifying Modular and Integrative Systems and Their Impact on Design Team Interactions. Journal of Mechanical Design 125, 240.

Sosa, M.E., Eppinger, S.D., Rowles, C.M., 2004. The Misalignment of Product Architecture and Organizational Structure in Complex Product Development. Management Science 50, 1674-1689.

Sosa, M.E., Eppinger, S.D., Rowles, C.M., 2007. Are your engineers talking to one another when they should? Harvard Business Review 133-142.

Steward, D. V, 1981. The Design Structure System: A Method for Managing the Design of Complex Systems. IEEE Transactions on Engineering Management 28, 71-74. 
Tan, P.-N., 2006. Cluster Analysis: Basic Concepts and Algorithms. In: Introduction to Data Mining. Pearson Addison Wesley, Boston, pp. 487-568.

Tsai, W., 2001. Knowledge transfer in intraorganizational networks: effects of network position and absorptive capacity on business unit innovation and performance. Academy of Management Journal 44, 996-1004.

Tushman, M.L., Katz, R., Ralph, A., 1980. External communication and project performance: an investigation into the role of gatekeepers. Management Science 26, 1071-1086.

Wasserman, S., Faust, K., 1994. Social Network Analysis: Methods and Applications. Cambridge University Press, Cambridge.

Wynn, D.C., Caldwell, N.H., Clarkson, P.J., 2014. Predicting Change Propagation in Complex Design Workflows. Journal of Mechanical Design 136.

Yassine, A.A., Falkenburg, D.R., Chelst, K., 1999. Engineering design management: An information structure approach. International Journal of Production Research 37, 2957-2975. 